A substantial number of hospitalized cases of cystic fibrosis with a relatively high fatality rate indicates one aspect of the health problem presented by this disease, first differentiated only some 20 years ago.

\title{
A National Hospital Survey of Cystic Fibrosis
}

\author{
MONROE G. SIRKEN, Ph.D., MARIAN M. CRANE, M.D., MORTON L. BROWN, B.A., \\ and ELIZABETH R. KRAMM, Ph.D.
}

C YSTIC FIBROSIS, also known as fibrocystic disease of the pancreas and as mucoviscidosis, has been increasingly recognized during recent years as one of the major diseases of childhood. As recently as 1938, Andersen (1) differentiated the disease from other superficially similar conditions. It is known to be a familial disease involving malfunction of various exocrine glands, but the basic defect underlying its pathological manifestations is not yet understood.

Clinically, cystic fibrosis is most often evidenced by chronic digestive and respiratory disturbances appearing usually in infancy or early childhood. Without treatment these generally progress to nutritional failure or severe respiratory involvement, or both, and to death before school age. Other manifestations include intestinal obstruction in the newborn, heat prostration, and, more rarely, cirrhosis of the liver. Cure is not possible, but with the use of recently

Dr. Sirken is chief and Mr. Brown is a statistician in the Actuarial Analysis and Survey Methods Section, National Office of Vital Statistics, Public Health Service. Dr. Crane is research pediatrician and Dr. Kramm is a health research specialist, Division of Research, Children's Bureau, Social Security Administration. The survey was supported in part by funds from the National In stitute of Allergy and Infectious Diseases, Public Health Service. developed methods of diagnosis and treatment prognosis has become more hopeful. When the disease is recognized in its early stages or in milder forms, development of serious symptoms can often be prevented. Antibiotics help to control the susceptibility to respiratory infection, but once pulmonary lesions are established they tend to persist and can be fatal or seriously handicapping.

The frequency of the disease in the general population is not known, but it appears to be high. On the basis of a small survey of hospitals and pediatricians, it was estimated that during the period $1945-49$ the disease occurred 7 to 10 times per 10,000 live births (2). The condition has been found in about 3 percent of the autopsies performed in children's hospitals (3). Early clinical experience with the disease indicated that death occurs in infancy or early childhood for a majority of positively diagnosed cases (4). Recently, however, survival beyond childhood of patients with cystic fibrosis has been noted with increasing frequency (5).

The Children's Bureau and the National Office of Vital Statistics are cooperating in a project designed to obtain information on the magnitude and characteristics of the health problem presented by cystic fibrosis. In the first phase of the study, reported here, data have been obtained by a mail survey on the number of children with a diagnosis of cystic fibrosis who were cared for in hospitals during 
the period 1952 through 1958. The next phase will be concerned primarily with the development and testing of methods for conducting a national epidemiological study of the disease.

The hospital survey was undertaken first not only because the need for hospital care is an important aspect of the health problem presented by this disease, but also because information about hospitalized patients is more readily available than any other data on prevalence since most hospitals maintain an index of diseases which makes possible the identification of cystic fibrosis patients. It is generally believed, however, that the number of hospitalized patients is only a fraction of the total number of children with the disease.

\section{Method}

The survey covered all hospitals in the continental United States listed in the American Hospital Association and the American Osteopathic Hospital Association directories for 1958, except psychiatric institutions. A stratified sample of about 9 percent, or 616 , of the 6,723 listed nonpsychiatric hospitals was selected. All 296 hospitals approved for pediatric residency were taken. A sample of other hospitals was selected with probability roughly proportionate to the number of hospital beds. The sampling rates ranged between 2 and 100 percent for the hospitals with the smallest and largest numbers of beds, respectively (table 1).

Questionnaires were sent by regular mail to the sample hospitals. Hospitals that did not return them within 2 weeks were sent a followup letter by certified mail. Toward the end of the fourth week of the survey, telephone calls were made to the larger hospitals with pediatric residencies that had not responded. Returned questionnaires were edited for completeness and consistency, and special letters were sent to hospitals that reported incomplete or inconsistent information. The survey lasted 5 weeks, from January 8 through February 13, 1959.

\section{Interpretation of Data}

The questionnaire requested information on the number of different patients discharged with a diagnosis of cystic fibrosis, the number of dis- charges for these patients, and the number of discharges that were due to death. Separate information was requested for each calendar year during the 7-year period 1952-58. Because cystic fibrosis (indexed under fibrocystic disease of the pancreas) was listed for the first time in the fourth edition of the American Medical Association's Standard Nomenclature of Diseases and Operations, published in 1952 (6), that year was chosen as the beginning of the study period. The standard nomenclature is the basis for disease indexing in the vast majority of hospitals in the United States. Additional information relating to the characteristics of the discharges for 1957 was also requested, but these data are not considered in this report. The final section of the form requested information about the type and currency of diagnostic indexing, which was useful in evaluating the quality of the reported data.

Evaluation of the quality of the data reported by the hospitals for the 6-year period 1952-57, shown in table 2, was based entirely on the completeness and consistency of the data on the returned form. Data for 1958 were excluded because a substantial number of hospitals had not yet completed their diagnostic indexing for that year. According to the evaluation criteria, about 80 percent of the hospitals reported complete and consistent information for the entire 6-year period. By the cutoff date no data were reported for almost 10 percent of the hospitals :

\section{Table 1. Sampling strata of the national hos-} pital survey of cystic fibrosis

\begin{tabular}{|c|c|c|c|}
\hline Type and size of hospital & $\begin{array}{l}\text { Sam- } \\
\text { pling } \\
\text { rate } \\
\text { (per- } \\
\text { cent) }\end{array}$ & $\begin{array}{l}\text { Num- } \\
\text { ber of } \\
\text { listed } \\
\text { hospi- } \\
\text { tals }\end{array}$ & $\underset{\text { size }}{\text { Sample }}$ \\
\hline $\begin{array}{l}\text { All hospitals in AHA } \\
\text { and AOHA direc- } \\
\text { tories (psychiatric } \\
\text { institutions ex- } \\
\text { cluded) }\end{array}$ & 9.16 & 6,723 & 616 \\
\hline $\begin{array}{l}\text { Hospitals with pediatric } \\
\text { residencies } \\
\text { Other hospitals. } \\
1,000 \text { or more beds } \\
300-999 \text { beds } \\
200-299 \text { beds } \\
100-199 \text { beds } \\
\text { Less than } 100 \text { beds. }\end{array}$ & $\begin{array}{r}100.00 \\
4.98 \\
100.00 \\
20.00 \\
10.00 \\
5.00 \\
2.00\end{array}$ & $\begin{array}{r}296 \\
6,427 \\
37 \\
425 \\
508 \\
1,197 \\
4,260\end{array}$ & $\begin{array}{r}296 \\
320 \\
37 \\
85 \\
51 \\
61 \\
86\end{array}$ \\
\hline
\end{tabular}


Table 2. Evaluation of hospital reporting in national survey of cystic fibrosis for period 1952-57, by type and size of hospital

\begin{tabular}{|c|c|c|c|c|c|c|}
\hline \multirow{3}{*}{ Type and size of hospital } & \multirow{3}{*}{$\begin{array}{c}\text { Sample } \\
\text { size }\end{array}$} & \multicolumn{5}{|c|}{ Percent of sample } \\
\hline & & \multirow{2}{*}{$\begin{array}{l}\text { Complete } \\
\text { and con- } \\
\text { sistent } \\
\text { data for } \\
\text { full period }\end{array}$} & \multirow{2}{*}{$\begin{array}{l}\text { Complete } \\
\text { and con- } \\
\text { sistent } \\
\text { data for } \\
\text { part of } \\
\text { period }\end{array}$} & \multicolumn{3}{|c|}{ No data } \\
\hline & & & & Total & $\begin{array}{l}\text { Non- } \\
\text { response }\end{array}$ & $\begin{array}{l}\text { Other } \\
\text { reasons }\end{array}$ \\
\hline $\begin{array}{l}\text { All hospitals in AHA and AOHA direc- } \\
\text { tories (psychiatric institutions ex- } \\
\text { cluded) }\end{array}$ & 616 & 79.5 & 11.0 & 9. 4 & 7. 0 & 2. 4 \\
\hline $\begin{array}{l}\text { Hospitals with pediatric residencies. } \\
\text { Other hospitals } \\
1,000 \text { or more beds } \\
300-999 \text { beds } \\
200-299 \text { beds } \\
100-199 \text { beds } \\
\text { Less than } 100 \text { beds }\end{array}$ & $\begin{array}{r}296 \\
320 \\
37 \\
85 \\
51 \\
61 \\
86\end{array}$ & $\begin{array}{l}\text { 79. } 1 \\
80.0 \\
83.8 \\
84.7 \\
66.7 \\
\text { 88. } 5 \\
75.6\end{array}$ & $\begin{aligned} 10.8 \\
11.3 \\
10.8 \\
8.2 \\
19.6 \\
8.2 \\
11.6\end{aligned}$ & $\begin{aligned} \text { 10. } 1 \\
8.8 \\
5.4 \\
7.1 \\
13.7 \\
3.3 \\
12.8\end{aligned}$ & $\begin{aligned} 7.1 \\
6.9 \\
2.7 \\
5.9 \\
9.8 \\
3.3 \\
10.5\end{aligned}$ & $\begin{array}{l}\text { 3. } \\
\text { 1. } 9 \\
\text { 2. } \\
\text { 1. } 2 \\
\text { 3. } 9 \\
0.9 \\
2.3\end{array}$ \\
\hline
\end{tabular}

7 percent did not respond and 2.4 percent indicated inability to comply with the request for data within the specified time. (About onefourth of the nonresponding hospitals replied within 1 month after the cutoff date but too late to be included in this analysis.) Another 11 percent of the hospitals returned forms which were evaluated as incomplete or inconsistent for 1 or more years between 1952 and 1957 .

One exception was made in evaluating the returned forms. A large pediatric residency hospital provided annual data for the number of patients discharged and the number of deaths but could not provide information on the total number of discharges within the time limits. Discharges were estimated by assuming a ratio between discharges and patients based on data reported by another large pediatric residency hospital.

As might have been expected, the reported hospital data were more complete and consistent for the more recent years. About 89 percent of the hospitals reported complete and consistent information for 1957 as compared with 82 percent for 1952 (table 3).

Tabulations of reported frequencies of patients, discharges, and deaths during 1957 were based solely on hospitals providing complete and consistent information for that year. The tabulated frequencies were appropriately adjusted for the hospitals excluded from the tabulations under the assumption that their expe-

Table 3. Percentage of hospitals reporting complete and consistent data on patients, deaths, and discharges with a diagnosis of cystic fibrosis, by type and size of hospital, 1952-57

\begin{tabular}{|c|c|c|c|c|c|c|c|}
\hline Type and size of hospital & Sample size & 1957 & 1956 & 1955 & 1954 & 1953 & 1952 \\
\hline $\begin{array}{l}\text { All hospitals in the AHA and AOHA } \\
\text { directories (psychiatric institutions } \\
\text { excluded) }\end{array}$ & 616 & 89 & 88 & 87 & 85 & 84 & 82 \\
\hline $\begin{array}{l}\text { Hospitals with pediatric residencies } \\
\text { Other hospitals } \\
1,000 \text { or more beds } \\
\text { 300-999 beds } \\
\text { 200-299 beds } \\
\text { 100-199 beds } \\
\text { Less than } 100 \text { beds }\end{array}$ & $\begin{array}{r}296 \\
320 \\
37 \\
85 \\
51 \\
61 \\
86\end{array}$ & $\begin{array}{l}88 \\
90 \\
97 \\
91 \\
84 \\
93 \\
86\end{array}$ & $\begin{array}{l}86 \\
89 \\
97 \\
91 \\
84 \\
95 \\
81\end{array}$ & $\begin{array}{l}87 \\
88 \\
95 \\
89 \\
82 \\
95 \\
80\end{array}$ & $\begin{array}{l}85 \\
85 \\
95 \\
87 \\
77 \\
92 \\
79\end{array}$ & $\begin{array}{l}84 \\
83 \\
89 \\
86 \\
75 \\
92 \\
78\end{array}$ & $\begin{array}{l}82 \\
82 \\
87 \\
85 \\
71 \\
92 \\
77\end{array}$ \\
\hline
\end{tabular}


Table 4. Estimated number of patients, discharges, and deaths with a diagnosis of cystic fibrosis reported by hospitals, United States, 1957

\begin{tabular}{r|r|r|r}
\hline Type of hospital & Patients & $\begin{array}{r}\text { Dis- } \\
\text { charges }\end{array}$ & Deaths \\
\hline All hospitals_....- & 2,525 & 3,229 & 359 \\
\hline $\begin{array}{r}\text { Hospitals approved for } \\
\text { pediatric residency }\end{array}$ & 1,186 & 1,544 & 237 \\
Other hospitals_-...-- & 1,339 & 1,685 & 122 \\
\hline
\end{tabular}

rience was the same as that reported by hospitals included. The adjusted frequencies were subsequently inflated by the inverse of the sampling rate to obtain the national estimates presented in this report. The adjustment and inflation of the tabulated frequencies were made independently for each sampling stratum. Data for two hospitals which specialized in research on cystic fibrosis and which reported the highest caseloads were excluded prior to adjusting the estimates for nonreporting hospitals approved for pediatric residency. The trend figures for 1952-57 were based on hospitals providing complete and consistent information for the 6-year period, and the frequencies were adjusted and inflated as for the 1957 data.

A qualifying statement is necessary regarding the estimates of the number of cystic fibrosis patients presented in this report. The hospitals were requested to report the number of different patients who were discharged each year. No attempt was made, however, to obtain identifying data on individual cases such as would be needed to eliminate duplicate re-

porting of cases from year to year within the same hospitals or from different hospitals within the same year.

Since the survey was conducted with a sample of hospitals, the estimates presented in this report are subject to sampling errors. The approximate sampling errors in the estimates of patients, discharges, and deaths for 1957 are shown below. The chances are about 19 out of 20 that differences due to sampling variability between the estimate based on the sample of hospitals and the figure that would have been obtained from a survey of all hospitals is less than twice the sampling error. The sampling errors of the estimates for other years were roughly the same as those for 1957 .

Type of hospital

All hospitals

Hospitals not approved for pediatric residency

\begin{tabular}{ccr}
\multicolumn{3}{c}{ Percent sampling error } \\
\hline \multicolumn{3}{c}{ Dis- } \\
Patients & charges & Deaths \\
10 & 10 & 10 \\
& & \\
20 & 20 & 30
\end{tabular}

\section{Estimates for 1957}

About 2,500 patients with a diagnosis of cystic fibrosis were discharged from hospitals in the United States during 1957 (table 4). This estimate is probably somewhat higher than the true figure because patients discharged with this diagnosis from more than one hospital during 1957 were counted by each hospital. Approximately 95 percent of the 2,500 patients were under 20 years of age. For these 2,500 patients, about 3,200 discharges were reported, indicating multiple discharges from the same hospital during 1957 for many of them. About 360 hospital deaths were attributed to cystic fibrosis, or ap-

Table 5. Trend in the estimated number of patients, discharges, and deaths with a diagnosis of cystic fibrosis, by type of hospital, United States, 1952-57

\begin{tabular}{|c|c|c|c|c|c|c|}
\hline \multirow{2}{*}{ Year } & \multicolumn{3}{|c|}{ All hospitals } & \multicolumn{3}{|c|}{ Pediatric residency hospitals } \\
\hline & Patients & Discharges & Deaths & Patients & Discharges & Deaths \\
\hline $\begin{array}{l}1957 \\
1956 \\
1955 \\
1954 \\
1953 \\
1952\end{array}$ & $\begin{array}{l}2,525 \\
2,611 \\
2,112 \\
2,379 \\
1,900 \\
1,687\end{array}$ & $\begin{array}{l}3,229 \\
3,375 \\
2,638 \\
2,981 \\
2,309 \\
2,107\end{array}$ & $\begin{array}{l}359 \\
451 \\
475 \\
387 \\
371 \\
295\end{array}$ & $\begin{array}{l}1,186 \\
1,210 \\
1,170 \\
1,127 \\
1,101 \\
981\end{array}$ & $\begin{array}{l}1,544 \\
1,586 \\
1,490 \\
1,425 \\
1,487 \\
1,259\end{array}$ & $\begin{array}{l}237 \\
237 \\
248 \\
205 \\
234 \\
198\end{array}$ \\
\hline
\end{tabular}


Figure 1. Trend in the number of patients and discharges with a diagnosis of cystic fibrosis from hospitals, United States, 1952-57

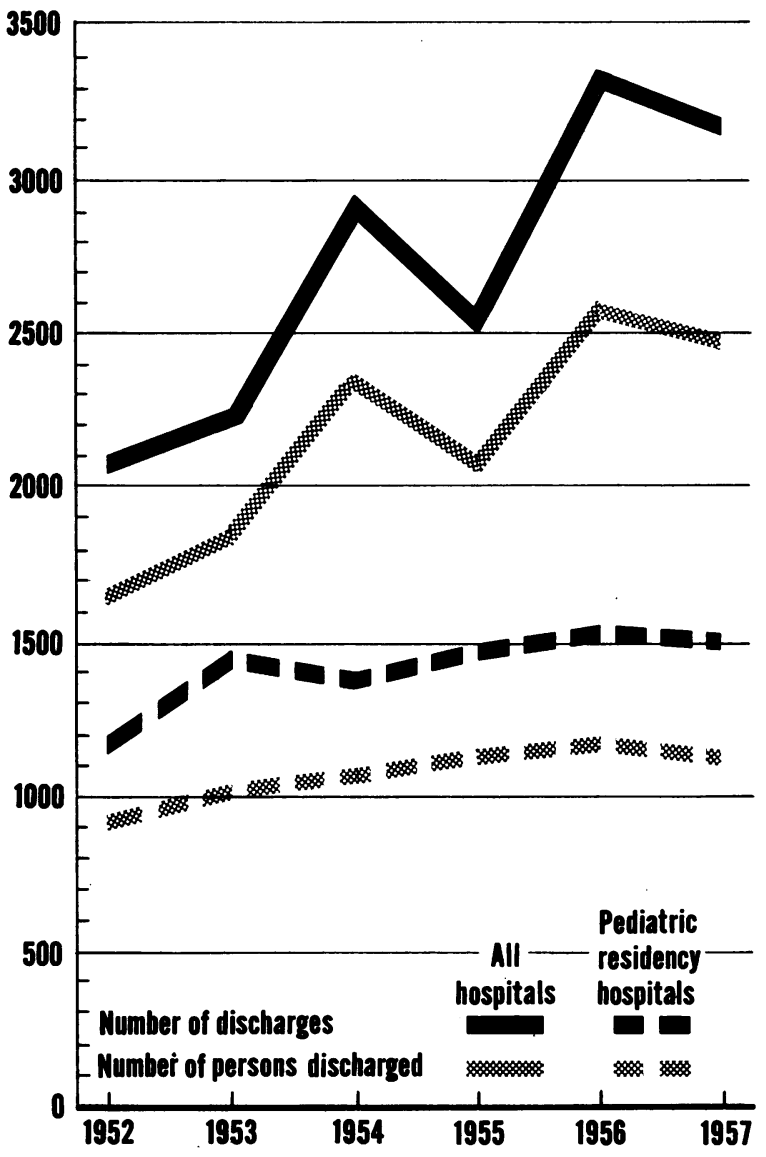

proximately 1 out of every 7 patients with the diagnosis.

Although hospitals with pediatric residencies represented less than 5 percent of all hospitals, they accounted for almost 50 percent of the patients and discharges and almost 65 percent of the deaths (table 4). The two children's hospitals, Babies Hospital in New York City and Children's Medical Center in Boston, in which physicians have for a long time had special interest in this disease, accounted for about 6 percent of the patients and discharges and 7 percent of the deaths reported for 1957.

\section{Trends for 1952-57}

The annual number of patients with cystic fibrosis increased by about 50 percent during the 6 -year period 1952-57, or from about 1,700 to about 2,500 (table 5, fig. 1). During the same period the population under 20 years of age, which included virtually all the diagnosed cases of cystic fibrosis, increased only between 15 and 20 percent. Most of the increase in cystic fibrosis patients occurred in hospitals not approved for pediatric residency, the number in pediatric residency hospitals remaining relatively constant during the entire period.

The number of discharges also increased by about 50 percent, or from 2,100 in 1952 to about 3,200 in 1957 , and again most of the increase occurred in nonpediatric hospitals (table 5, fig. 1).

The number of hospital deaths attributed to cystic fibrosis reached a peak during 1955 and then declined in 1957 (table 5, fig. 2). During the 6-year period, the proportion of deaths ranged between 14 and 25 percent of the total number of patients discharged with the disease. It is difficult, however, to draw conclusions about the death trend from these data since most of the annual changes in the number of deaths in hospitals may reflect sampling variability.

\section{Discussion}

This survey has provided data on the number of patients with a diagnosis of cystic fibrosis discharged from hospitals in the United States for each of the 6 years from 1952 through 1957. However, the numbers for individual years cannot be added together to obtain a total for the period since the same persons could have been reported for 2 or more years. Even within a single year there could have been duplicate reporting for patients discharged from more than one hospital during that year.

In the years covered by the survey there has been a continuous and substantial increase in the annual number of patients hospitalized with a diagnosis of cystic fibrosis. Since this increase is about three times greater than the increase in the size of the population under 20 years of age, it is only partially explained by this factor. The increase may be interpreted as indicating greater success in recognizing the disease. Most of the increase is reported from hospitals that do not have a pediatric residency and is probably the result of an increased awareness of the disease outside pediatric 
Figure 2. Trend in the number of deaths attributed to cystic fibrosis in hospitals, United States, 1952-57

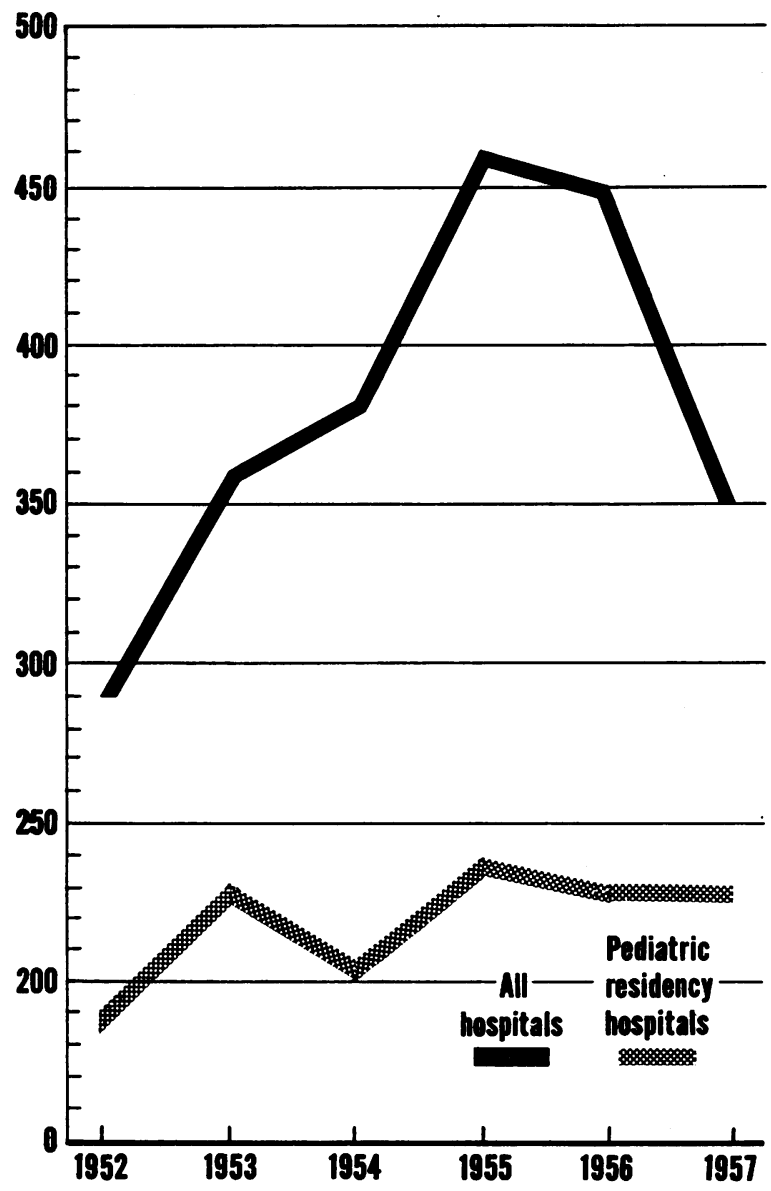

centers. Greater awareness on the part of physicians and improved diagnostic techniques have resulted in earlier recognition of the milder forms of the disease, many of which do not require hospitalization. The cystic fibrosis patients hospitalized in 1957, therefore, probably represented a smaller proportion of the total number of cases known to physicians than did the patients hospitalized in 1952, even though the number of persons hospitalized for the disease had increased 50 percent from 1952 to 1957.

Data are yet to be obtained on the ratio of persons hospitalized with cystic fibrosis to total persons with the disease. There are diagnosed cases which have not been admitted to a hospital as well as undiagnosed cases. Concerning the former, Dr. Harry Shwachman of the Children's Medical Center in Boston, a center long known for its interest in cystic fibrosis, has estimated that of the 500 children with this condition followed in his office or clinic practice, at least 25 percent have never been hospitalized. Dr. Gordon E. Gibbs in the department of pediatrics of the University of Nebraska has stated that of 40 children with cystic fibrosis directly or indirectly under his care only 4 have ever been admitted to a hospital. It seems likely that the 2,500 cystic fibrosis patients discharged from hospitals in the year 1957 represent only a small part of the total number of patients with the disease, although the exact proportion is still uncertain.

That the number of hospital discharges with a diagnosis of cystic fibrosis is nearly a third greater than the number of persons so discharged in the same year indicates that many of the patients are so ill as to need repeated hospital admissions within a short period. On the basis of an estimated 2,800,000 hospital discharges for patients under 15 years of age from July 1957 through June 1958 ( 7$)$, cystic fibrosis was the diagnosis of roughly 1 in every 1,000 hospital discharges among children.

The estimate of the number of annual hospital deaths attributed to cystic fibrosis obtained from this survey is supported by information from another source. The National Office of Vital Statistics has obtained an estimate of the number of deaths attributed to cystic fibrosis by coding the disease separately in its analysis of a 10 percent sample of 1958 death certificates. Such data have not been obtained nationally in previous analyses of death certificates because cystic fibrosis has hitherto been included in the residual category "Other diseases of pancreas."

Analysis of the sample of 1958 death certificates revealed an estimated 560 deaths in the United States attributed to cystic fibrosis in that year. Of these, about 400 occurred in hospitals. With due regard to sampling error, this is consistent with the finding from the hospital survey of an estimated 359 hospital deaths attributed to cystic fibrosis in 1957. The finding that about 160 (over one-fourth) of the cystic fibrosis deaths reported on 1958 death certificates occurred outside hospitals is evidence that the children are not always hospitalized even during the most acute phases of the illness. 
Estimates of 1958 deaths by cause for the population under 15 years indicate that cystic fibrosis ranked higher as a cause of death than such other diseases as diabetes, rheumatic fever, and poliomyelitis. Cystic fibrosis is comparable to these diseases not only as a cause of death but also in the lasting and handicapping disability it often causes in patients who survive.

\section{Summary}

A nationwide hospital sample survey, conducted between January 8 and February 13, 1959, obtained information about hospital patients discharged with cystic fibrosis. The survey provided the following national estimates:

1. In 1957, about 2,500 patients were discharged from hospitals with a diagnosis of cystic fibrosis. Of these, 95 percent were under 20 years of age. The total number of discharges for that year was approximately 3,200, indicating repeated hospitalization for many of the patients. About 360, or 14 percent of the patients, were discharged by death. (A sample of 1958 death certificates indicated that roughly one-fourth of all deaths due to cystic fibrosis occur outside hospitals.)

2. From 1952 to 1957 , the number of hospitalized patients with the disease increased by approximately 50 percent. There was a corresponding increase in the total number of discharges. Most of the increase in the number of patients and discharges occurred in hospitals other than those approved for pediatric residency. The estimated number of deaths in 1957 was approximately 20 percent greater than the estimate for 1952, but this difference may be attributed to sampling error. During the intervening years, a somewhat higher number of deaths was reported.

Although estimates of the number of patients discharged from hospitals with a diagnosis of cystic fibrosis are probably far short of the prevalence of the disease in the general population, the fact that in 1 year 2,500 persons were hospitalized and that 1 out of every 6 or 7 was discharged by death affords a striking picture of the seriousness of this disease.

\section{REFERENCES}

(1) Andersen, D. H.: Cystic fibrosis of the pancreas and its relation to celiac disease. A clinical and pathologic study. Am. J. Dis. Child. 56: 344-399, August 1938.

(2) Goodman, H. O., and Reed, S. C.: Heredity of fibrosis of the pancreas. Possible mutation rate of the gene. Am. J. Human Genet. 4: 59-71, June 1952.

(3) Andersen, D. H., and Hodges, R. G.: Celiac syndrome. V. Genetics of cystic fibrosis of the pancreas with a consideration of etiology. Am. J. Dis. Child. 72 : 62-80, July 1946.

(4) Andersen, D. H.: Cystic fibrosis of the pancreas. J. Chronic Dis. 7 : 58-90, January 1958.

(5) Shwachman, H., and Kulczycki, L. L.: Long-term study of one hundred five patients with cystic fibrosis. A.M.A. Am. J. Dis. Child. 96: 6-15, July 1958.

(6) Plunkett, R. J., and Hayden, A. C., Editors: Standard nomenclature of diseases and operations. Ed. 4. New York, Blakiston Co., 1952, $1,034 \mathrm{pp}$.

(7) U.S. Public Health Service: Health statistics from the U.S. National Health Survey. Hospitalization: Patients discharged from shortstay hospitals, United States, July 1957-June 1958. PHS Pub. No. 584-B7. Washington, D.C., U.S. Government Printing Office, 1958, 40 pp. 